\title{
Early Diagnosis of Vegetation Health From High-Resolution Hyperspectral and Thermal Imagery: Lessons Learned From Empirical Relationships and Radiative Transfer Modelling
}

\author{
R. Hernández-Clemente ${ }^{1} \cdot$ A. Hornero ${ }^{1} \cdot$ M. Mottus $^{2} \cdot$ J. Penuelas $^{3,4} \cdot$ V. González-Dugo ${ }^{5} \cdot$ J. C. Jiménez ${ }^{6} \cdot$ L. Suárez $^{7}$. \\ L. Alonso ${ }^{8}$ P. P. J. Zarco-Tejada ${ }^{5,7}$
}

Published online: 20 August 2019

(C) The Author(s) 2019

\begin{abstract}
Purpose of Review We provide a comprehensive review of the empirical and modelling approaches used to quantify the radiationvegetation interactions related to vegetation temperature, leaf optical properties linked to pigment absorption and chlorophyll fluorescence emission, and of their capability to monitor vegetation health. Part 1 provides an overview of the main physiological indicators (PIs) applied in remote sensing to detect alterations in plant functioning linked to vegetation diseases and decline processes. Part 2 reviews the recent advances in the development of quantitative methods to assess PI through hyperspectral and thermal images.

Recent Findings In recent years, the availability of high-resolution hyperspectral and thermal images has increased due to the extraordinary progress made in sensor technology, including the miniaturization of advanced cameras designed for unmanned aerial vehicle (UAV) systems and lightweight aircrafts. This technological revolution has contributed to the wider use of hyperspectral imaging sensors by the scientific community and industry; it has led to better modelling and understanding of the sensitivity of different ranges of the electromagnetic spectrum to detect biophysical alterations used as early warning indicators of vegetation health.

Summary The review deals with the capability of PIs such as vegetation temperature, chlorophyll fluorescence, photosynthetic energy downregulation and photosynthetic pigments detected through remote sensing to monitor the early responses of plants to different stressors. Various methods for the detection of PI alterations have recently been proposed and validated to monitor vegetation health. The greatest challenges for the remote sensing community today are (i) the availability of high spatial, spectral and temporal resolution image data; (ii) the empirical validation of radiation-vegetation interactions; (iii) the upscaling of physiological alterations from the leaf to the canopy, mainly in complex heterogeneous vegetation landscapes; and (iv) the temporal dynamics of the PIs and the interaction between physiological changes.
\end{abstract}

Keywords Vegetation health $\cdot$ Hyperspectral and thermal data $\cdot$ Physiological indicators $\cdot$ Radiative transfer models $\cdot$ Vegetation indices

This article is part of the Topical Collection on Remote Sensing

R. Hernández-Clemente

r.hernandez-clemente@swansea.ac.uk

1 Department of Geography, Swansea University (SU), Swansea SA2 $8 \mathrm{PP}, \mathrm{UK}$

2 Technical Research Centre of Finland (VTT), P.O. Box 1000, FI-02044 Espoo, Finland

3 Centro de Investigación Ecológica y Aplicaciones Forestales (CREAF), 08193 Cerdanyola del Valles, Catalonia, Spain

4 Consejo Superior de Investigaciones Científicas (CSIC), Global Ecology Unit CREAF-CSIC-UAB, 08193 Bellaterra, Catalonia, Spain
5 Instituto de Agricultura Sostenible (IAS), Consejo Superior de Investigaciones Científicas (CSIC), s/n 14004 Alameda del Obispo, Cordoba, Spain

6 University of Valencia (GCU/IPL), Catedrático José Beltrán 2, 46980 Paterna, Valencia, Spain

7 School of Agriculture and Food, Faculty of Veterinary and Agricultural Sciences (FVAS) \& Department of Infrastructure Engineering, Melbourne School of Engineering (MSE), University of Melbourne, Parkville, Victoria 3010, Australia

8 University of Valencia, Valencia, Spain 


\section{Introduction}

This review focuses on the recent progress in remote sensing detection of early responses of plants to biotic and abiotic stresses. One of the main challenges for the research community is to develop viable detection methods to anticipate long-term irreversible damage to stressed vegetation before symptoms are visible so that action can be taken [1]. At an early stage of stress, alterations in the photosynthetic rate and stomatal conductance affect sun radiation-vegetation interactions, including the energy dissipated as heat or emitted at longer wavelengths as chlorophyll fluorescence, and the gradual effects on the photosynthetic pigment concentration in plant leaves. Recent studies have demonstrated the capability of spectral data to detect physiological alterations and anticipate vegetation diseases such as Phytophthora [2], Xylella fastidiosa [3••], Verticillium wilt [4] and almond red leaf blotch [5], as well as environmental stressors such as water stress [6]. These achievements represent a major step forward in the monitoring of vegetation health from airborne remote sensing imagery and its potential application to satellite scales. Therefore, this review focuses on recent developments in the early detection of biotic- and abiotic-induced symptoms using hyperspectral and thermal images. It describes four groups of physiological indicators (PIs) of critical importance in plant functioning for improving vegetation monitoring: (i) vegetation temperature, (ii) chlorophyll fluorescence, (iii) photoprotective pigments or the xanthophyll cycle and (iv) photosynthetic pigments (Fig. 1).

\section{Part 1: Physiological Indicators of Vegetation Health}

New strategies using the radiation pathways of the photonvegetation interaction have recently been proposed as a way to detect plant physiological status through remote sensing. Light energy absorbed by vegetation can be used for photosynthesis, re-emitted as sun-induced fluorescence (SIF) or dissipated as heat. Any alteration in the efficiency of one of the components will affect the other two. Light re-emitted as SIF is produced by the pigment-protein complex photosystems I (PSI) and II (PSII) involved in photosynthesis. Although SIF is a small emission (2-3\% of the incoming radiation), it is a strong proxy for plant photosynthesis. Plant responses to environmental stress (e.g. light, nutrients, water availability, extreme temperatures) affect the photosynthetic rate and therefore fluorescence emission. For this reason, SIF has been used for decades as a powerful non-invasive marker to track the status, resilience and recovery of vegetation [7].

Additionally, vegetation temperature is related to stomatal conductance and transpiration-associated evaporative cooling. Specifically, when stomatal conductance decreases due to stoma closure under water stress conditions, vegetation temperature increases and the transpiration rate decreases accordingly. Consequently, vegetation temperature has been used to derive information about transpiration and as an indicator of vegetation health. The first study using this approach was conducted in 1964 on Quercus macrocarpa and demonstrated the suitability of temperature to monitor transpiration [8]. Since this pioneering research, vegetation temperature has

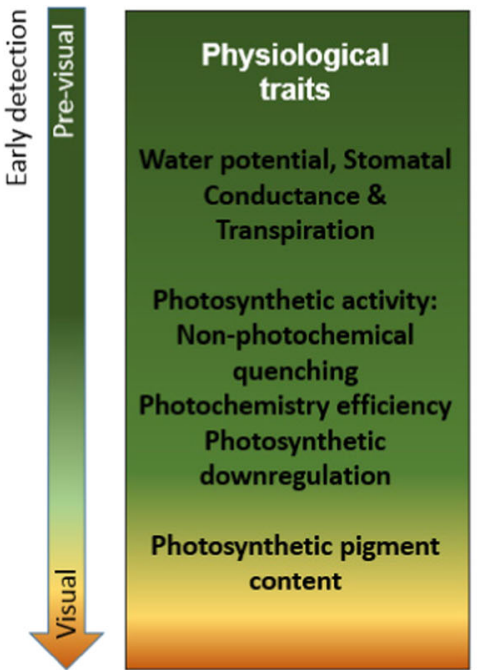

Fig. 1 Physiological indicators used to quantify early-stage vegetation health from hyperspectral and thermal data. Retrieval methods for four physiological-based groups used as indicators in remote sensing include (i) the difference between crown temperature and air temperature ( $\mathrm{Tc}-$

Ta), the crop water stress index (CWSI) and the water deficit index

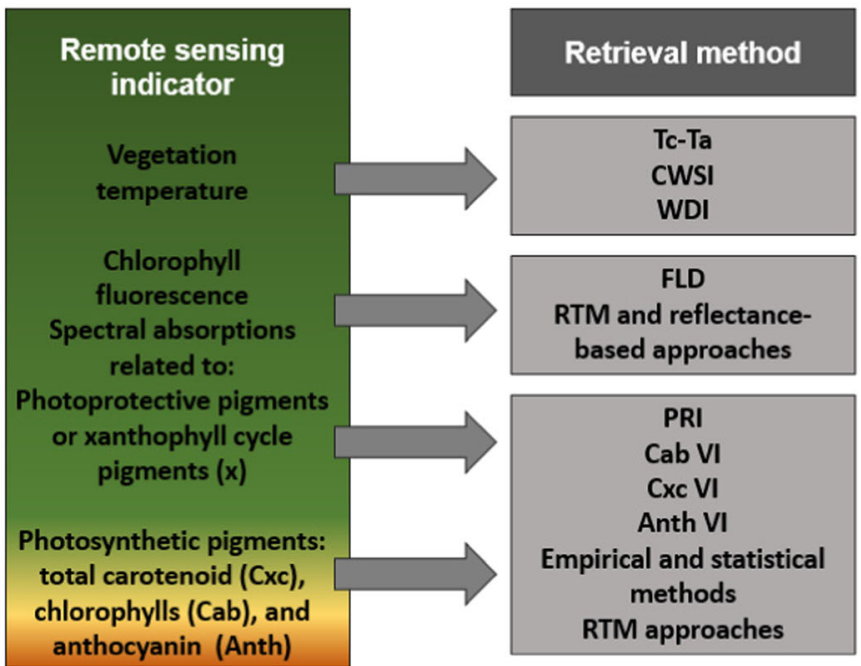

(WDI); (ii) the Fraunhofer line depth principle (FLD); (iii) the photochemical reflectance index (PRI); and (iv) the chlorophyll (Cab), carotenoid (Cxc) and anthocyanin (Anth) vegetation indices (VI), and radiative transfer models (RTM) 
been used to determine water status $[9,10]$, irrigation requirements in agriculture [11] and pest and disease incidence [3••, $12 \bullet \bullet, 13]$ and forest decline [14]. Compared to point groundbased measurements, the ability to remotely detect temporal and spatial variations in vegetation temperature as an indicator of water stress is considered a major advantage. Moreover, the relation between transpiration and vegetation temperature is underpinned by the energy balance equation [15], which implies the balance between incoming energy and energy loss and provides a theoretical basis for modelling methods and applications.

Various mechanisms overcome the excessive reduction of the light energy transferred when photosynthesis is reduced by stress or limited resources. These mechanisms downregulate the rate of electron transport in plant cells and dissipate excess energy controlling the facultative pool of xanthophyll pigments in plants known as facultative changes. The dissipation of excess energy by facultative non-photochemical quenching (NPQ) through the xanthophyll cycle is one of these mechanisms. NPQ is particularly interesting because it can provide an optical signal of excess of reducing power, increased NADPH/ NADP ratios and reduced light-use efficiency (LUE). Therefore, NPQ is linked to stress, caused by limited resources, and to the plant photosynthetic activity through associated changes in reflectance in the blue and green regions of the spectrum [16]. When excess excitation energy accumulates in the leaf, the chloroplast thylakoid $\mathrm{pH}$ gradient builds up and the xanthophyll cycle is activated: violaxanthin is de-epoxidized to zeaxanthin via antheraxanthin. These chemical changes affect the spectrally selective absorption of light, the relative absorption by each pigment and hence the leaf spectral reflectance and transmittance factors. These changes in reflectance result from changes in the de-epoxidation state of the xanthophylls, with increases in the concentration of zeaxanthin and consequent decreases in reflectance around $531 \mathrm{~nm}$.

Increasing levels of vegetation stress over time can ultimately cause variations among leaf photosynthetic pigment pools known as constitutive changes. The discolouration produced by the variation in pigment content has also been used as an indicator of vegetation health [17•]. The three main pigment groups are composed of chlorophylls, carotenoids and anthocyanins. Chlorophyll occurs in the form of chlorophyll a (Chla) as the major pigment and chlorophyll $\mathrm{b}$ (Chlb) as the accessory pigment. Both are genuine components of the photosynthetic membrane and occur in a ratio $a / b$ value between 1 and 4 reflecting growth and stress [18, 19]. Drought stress led to a decrease in Chla and Chlb and increase in the $\mathrm{Chl} \mathrm{a} / \mathrm{b}$ ratio due to greater reduction in Chlb compared to Chla. Carotenoids provide structure to the photosynthetic membrane, and play a role in light harvesting processes, energy transfer and NPQ through the xanthophyll cycle [20]. Anthocyanins are water- soluble flavonoids involved in plant protection against drought and stress [21] and photooxidative processes [2, 22] with an exponential decay with increases in Chlab content. Their assessment has typically been conducted in the context of senescence and fruit-ripening processes [23-25].

\section{Part 2: Retrieval Methods and Applications to Vegetation Health}

Given the importance that vegetation functioning plays in the monitoring of vegetation health, great efforts have been directed towards non-destructive retrieval methods at different spatial scales using various sensors and analytical methods. Figure 2 shows an example of the main PIs used for monitoring vegetation health that can be quantified with hyperspectral and thermal images using a broad range of approaches described below.

\section{Vegetation Temperature}

Vegetation temperature (VT) is a key indicator for vegetation health monitoring and several related applications have been identified [27]. However, accurate retrieval of VT from remote sensing data requires an accurate atmospheric correction. The main problem in obtaining accurate VT retrieval is the coupling between land surface temperature (LST) and land surface emissivity (LSE). Retrieval of vegetation emissivity is also of interest because the emissivity spectrum of vegetation provides information about leaf composition and health status [28].

Several LST (and LSE) retrieval methods have been published in recent decades (see a review by Li et al. [29]). These methods can be classified according to the spectral configuration of the thermal infrared (TIR) sensor. Hence, singlechannel (SC) algorithms have been developed for LST retrieval from a single TIR band, such as the previous Landsat series [30]. However, these methods are typically very sensitive to uncertainties in the atmospheric correction (e.g. in humid atmospheres). This problem of atmospheric correction in SC algorithms can partly be solved when two TIR bands are available. This is the case of the two-channel (TC) or splitwindow (SW) algorithms. These algorithms perform the atmospheric correction based on the differential absorption between two TIR bands located in atmospheric windows and usually provide robust retrievals in all types of conditions. An example is LST products generated from TIR data acquired by polar-orbiting or geostationary meteorological satellites (e.g. MetOp, Meteosat, GOES) and the recent Sentinel3. Both SC and TC algorithms require a priori knowledge of surface emissivity, which can be retrieved from vegetation indices and/or data measured in other parts of the electromagnetic spectrum [31]. 


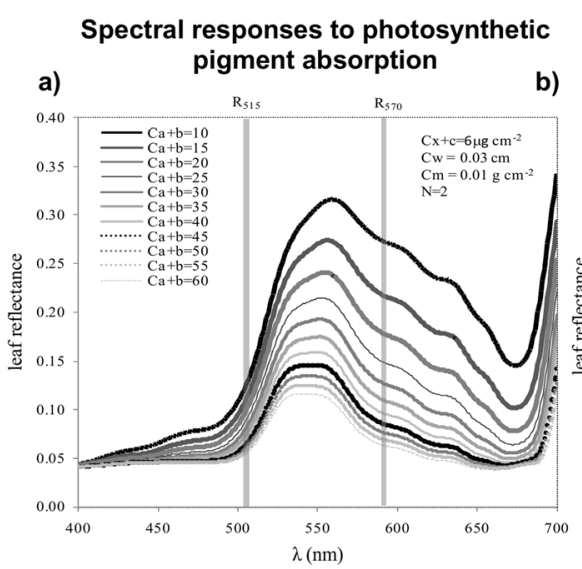

Non-photochemical quenching and chlorophyll fluorescence emission

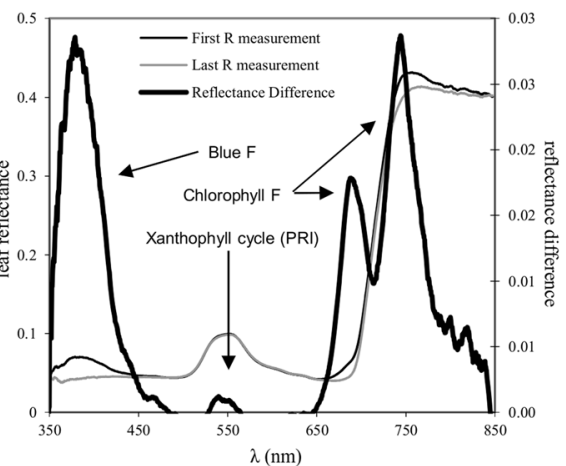

$\lambda(\mathrm{nm})$

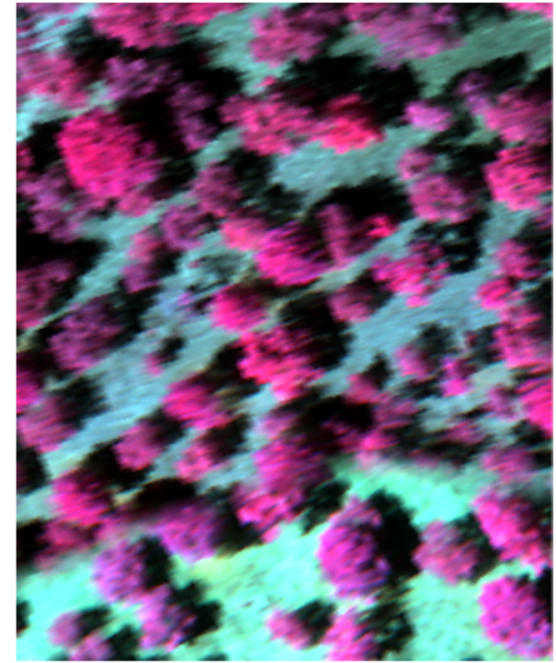

d)

VHR hyperspectral subset (CIR)

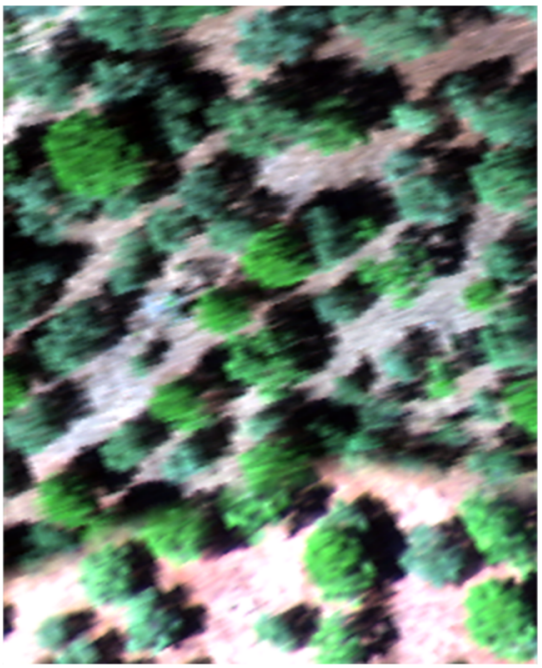

VHR hyperspectral subset (RGB)
Vegetation temperature

c)

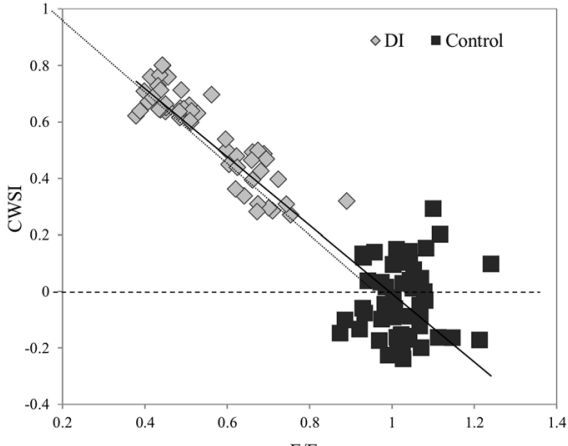

$\mathrm{E} / \mathrm{Ep}$

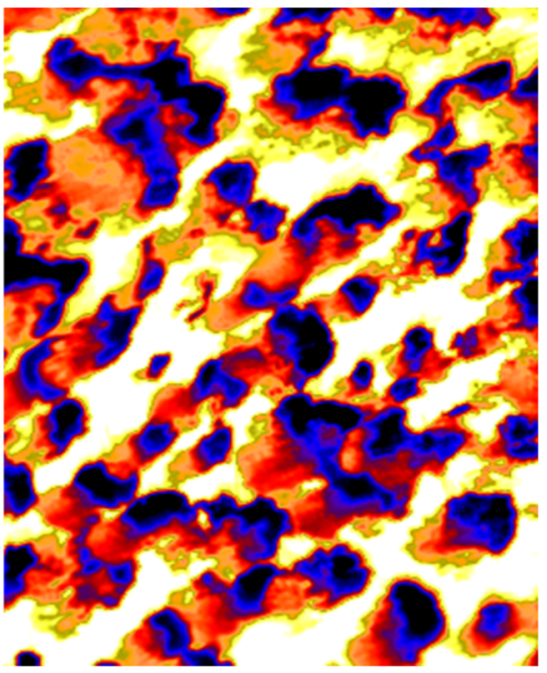

VHR thermal subset
Fig. 2 Pre-visual physiological indicators based on hyperspectral and thermal data: a leaf reflectance alterations in the visible and infrared ranges produced by the variation in chlorophyll content $(10-60 \mu \mathrm{g} /$ $\mathrm{cm}^{-2}$ ) [6]; b reflectance difference after light excitation showing the non-photochemical quenching and chlorophyll fluorescence emission

The innovation of multispectral TIR sensors (with three or more TIR bands in atmospheric windows) has encouraged the development of temperature and emissivity separation (TES) methods for simultaneous retrieval of LST and band emissivities. This is the case of the TES algorithm developed for ASTER [32] and also adapted to other satellite sensors such as MSG/SEVIRI [33] and Terra\&Aqua/MODIS [34]. In principle, TES methods are preferred for emissivity retrieval because they are extracted from TIR data, thus reflecting the actual conditions of the surface [35]. TES methods have also been applied to hyperspectral TIR data, usually acquired from airborne sensors or ground-based instruments based on Fourier transform infrared (FTIR) spectroscopy. Some of these techniques are based on spectral smoothness [36]. Emissivity spectrum retrieval from hyperspectral TIR imaging or FTIR laboratory spectroscopy has led to the use of emissivity spectral features for identification of plant species [28] and changes in canopy leaf area index [37]. on vegetation [26]; $\mathbf{c}$ relationship between the crop water stress index (CWSI) measured with infrared thermal sensors (IRT) sensors and the ratio between daily values of actual to potential transpiration $(E / E p)$ in mandarin trees in deficit-irrigated (DI) and well-irrigated (control trees) conditions; $\mathbf{d}$ high-resolution hyperspectral and thermal images

In the 1980s, Idso and Jackson's group demonstrated the need to normalize vegetation temperature according to environmental conditions. Air temperature, relative humidity and solar radiation strongly influence the absolute value of vegetation temperature and should, therefore, be considered in deriving any information about vegetation health. The final formulation developed by Idso et al. [38] to account for the influence of environmental conditions on vegetation temperature was termed crop water stress index (CWSI). This index is derived from the energy balance and relies on normalization according to air temperature and two bounding limits (Eq. 1):

CWSI $=\frac{(\mathrm{Tc}-\mathrm{Ta})-(\mathrm{Tc}-\mathrm{Ta})_{\mathrm{LL}}}{(\mathrm{Tc}-\mathrm{Ta})_{\mathrm{UL}}-(\mathrm{Tc}-\mathrm{Ta})_{\mathrm{LL}}}$

where $(\mathrm{Tc}-\mathrm{Ta})_{\mathrm{LL}}$ is the lower limit of the differential between vegetation and air temperature and corresponds to the $\mathrm{Tc}-\mathrm{Ta}$ value of the vegetation transpiring at the 
potential rate. $(\mathrm{Tc}-\mathrm{Ta})_{\mathrm{UL}}$ is the vegetation differential when transpiration is completely halted.

The CWSI can be determined empirically by assessing the value of the lower and upper limits or by modelling the energy balance at the canopy level [39]. In the empirical approach, the lower limit is computed using the non-water stress baseline (NWSB), which accounts for the relationship between the vapour pressure deficit (VPD) and the Tc-Ta value of the vegetation transpiring at the potential rate. It is speciesspecific and is affected by climatic conditions; thus, the extrapolation is restricted by the environment. For some species, it also varies according to plant phenology [40]. It can be determined by the continuous monitoring of temperature in plants that are not limited by water availability. The upper limit can be calculated by solving the NWSB equation for $\mathrm{VPD}=0$, and subsequently correcting for the difference in vapour pressure induced by the difference in temperature $\mathrm{Tc}-\mathrm{Ta}[38]$. The required inputs are limited to vegetation and air temperature and the VPD. However, this method has several limitations. First, the NWSB should be determined before the practical application of the CWSI is implemented. When the NWSB is not available for a specific species/ environment combination, the Tc value of plants transpiring at the potential rate must be known, ideally by determining the NWSB during the season. Moreover, as the CWSI is not normalized by the solar radiation, the measurement must be acquired under cloudless conditions and at midday to minimize this effect and obtain more robust estimates [41]. This can be a significant drawback in humid or temperate regions [39].

In its simplest form, the CWSI can also be determined directly by measuring the temperature of a wet (Twet) or dry surface [42]. These surfaces are included in the image and can be leaves either sprayed with water (Twet) or covered with petroleum jelly (Tdry), or an artificial surface with a thermal behaviour similar to that of the canopy. Although this method is very appealing because it does not require meteorological measurements, its accuracy is strongly affected by the references used, as Twet is often lower than potential $T$ [39]. Moreover, there is a scale issue, as the surface references usually have the size of a leaf and are thus used at the plant level, making the upscaling to airborne imagery difficult [43].

The CWSI can also be determined theoretically by deriving it from the energy balance (Eq. (2)), as proposed by Jackson et al. [44]:

$\mathrm{CWSI}=1-E / E_{p}=\frac{\gamma \cdot\left(1+r_{c} / r_{a}\right)-\gamma^{*}}{\Delta+\gamma \cdot\left(1+r_{c} / r_{a}\right)}$

where $E$ and $E_{\mathrm{p}}$ are actual and potential transpiration, respectively, $\Delta$ is the slope of the saturated vapour pressuretemperature relationship, $\gamma$ is the psychrometric constant, $r_{\mathrm{a}}$ is the aerodynamic resistance and $r_{\mathrm{c}}$ is the canopy resistance to vapour transport. The complex data requirement is the main limitation on use of this approach. Compared with the empirical approach, it can be applied under a wider range of weather conditions, as the net radiation is incorporated into the formulation. It is especially relevant for humid environments.

In open canopies, the surface temperature is a composite of soil and vegetation, which makes the CWSI not reliable, hampering its application on local and regional scales. This problem was explored by Moran et al. [45], who introduced the water deficit index (WDI). The WDI is based on the vegetation index/temperature trapezoid. It combines spectral vegetation indices with surface temperature measurements to allow application of the CWSI theory to partially vegetated fields without data on foliage temperature. Nevertheless, this approach does not always work well when the goal is to detect subtle temperature changes associated with vegetation stress.

\section{Chlorophyll Fluorescence Emission}

Research carried out over the last 20 years has provided theoretical and experimental evidences that SIF can be retrieved from imaging spectroscopy and used as an indicator of plant photosynthetic activity. The SIF emission spectrum is maximum at $682 \mathrm{~nm}$ for the PSII and 700 to $750 \mathrm{~nm}$ for PSI. There are many different parameters retrieved from SIF. For instance, the integral of the spectral fluorescence radiance in the observation direction $(F)$ over the full retrieval range (e.g. $670-780 \mathrm{~nm}, 650-850 \mathrm{~nm}$ ) (FINT), the maximum value of $F$ in the red region (maxFR), the maximum value of $F$ in the far-red region (maxFFR), $F$ value at $687 \mathrm{~nm}(\mathrm{~F} 687), F$ value at $740 \mathrm{~nm}$ (F740) or $F$ value at $760 \mathrm{~nm}$ (F760). However, the retrieval of SIF from images is extremely challenging due to the small contribution of the emission to total radiance. Several methods have been developed to quantify SIF at the leaf and canopy levels. The most common approaches to retrieve SIF from reflected radiance under field conditions are (i) the Fraunhofer line depth principle or discriminator (FLD) [46] using radiance spectra from the $\mathrm{O}_{2}$ absorption bands; (ii) radiative transfer modelling (RTM); (iii) spectral fitting methods (SFM) and singular vector decomposition (SVD).

Initial attempts to track the effects of fluorescence emission on reflectance signatures were based on computing a combination of spectral reflectance bands: a band near the two maximum fluorescence emissions (about 685 and $740 \mathrm{~nm}$ ) and a reference band that is less affected. Some of the formulations have been validated in vegetation at the canopy level [26]: $R_{680} / R_{630}, R_{685} / R_{630}, R_{686} / R_{630}, R_{690} / R_{630}, D_{730} / D_{706}, D_{\lambda \mathrm{P}} /$ $D_{703}, R_{683}{ }^{2} /\left(R_{675} \times R_{691}\right)$ and $R_{685} / R_{655}, D_{705} / D_{722}$ and $D_{730} /$ $D_{706}, R_{690} / R_{600}$ and $R_{740} / R_{800}$.

The FLD method initially proposed for the $H$ absorption calculates SIF using the sun's irradiance and canopy radiance inside and outside the $\mathrm{O}_{2}$ absorption bands (such as the $\mathrm{O}_{2}-\mathrm{A}$ band at $760.5 \mathrm{~nm}$ ). The main limitation of this formulation is to assume that reflectance and fluorescence inside and outside 
the $\mathrm{O}_{2}-\mathrm{A}$ band are the same. Several methods have been used to improve the formulation and linearly correlate reflectance with fluorescence. Some examples using airborne image data are 3FLD [47], corrected FLD (cFLD) [48] and improved FLD (iFLD) [49] reviewed by [50]. By contrast, SFM and SVD use all available hyperspectral bands to quantify the contribution of fluorescence and reflectance [51].

One of the first attempts to model the effects of fluorescence emission on the radiance and reflectance signatures was made by the European Space Agency (ESA). ESA developed the FluorMOD leaf [52] and the canopy FluorSAIL [53] models, including the fluorescence excitation-emission matrix to simulate the fluorescence effects at the canopy level. FluorMODleaf was based on the widely used and validated PROSPECT leaf optical properties model. It required the input of the $\sigma \mathrm{II} / \sigma \mathrm{I}$ ratio, referring to the relative absorption cross-section of PSI and PSII, and the fluorescence quantum efficiency of PSI and PSII, $\tau$ I and $\tau$ II. This model was recently computationally improved with FLUSPECT [54]. The canopy model was based on the turbid medium SAIL model (FluorSAIL), modified to internally compute the illumination levels through the canopy.

Extensive work has been conducted with FluorSAIL in homogeneous canopies. Yet, progress has been made in the development of modelling methods to retrieve pure vegetation fluorescence from aggregated pixels with FluorFLIM using the linked FluorMODleaf-FluorSAIL with the geometric forest light interaction model (FLIM) [55]. Further strategies to quantify SIF from heterogeneous natural ecosystems have been limited by difficulties in simulating canopy structure, crown overlapping, mutual shading and multiple scattering between crowns. The development of the model SCOPE (Soil Canopy Observation, Photochemistry and Energy fluxes) model [56] improved the effect of the environment (e.g. sun position and biochemical composition of the vegetation). Nevertheless, SCOPE is still a 1-D model and therefore ignores the vertical and horizontal variations in surface characteristics. This limits its range of applications in heterogeneous ecosystems. To fill this gap, a 3-D canopy FluorFLIGHT RTM was proposed by Hernández-Clemente et al. [12••] to properly parameterize the heterogeneous canopy structure. This model proposes a novel approach by linking the FLUSPECT model to the 3-D raytracing model (FLIGHT) to estimate $F$ signals in heterogeneous forest canopies. Forest canopies are characterized by high horizontal and vertical heterogeneities.

Consequently, the radiative transfer within a forest canopy depends on the spatial distribution of the canopy elements relative to each other and the subsequent complex radiative processes such as multiple scattering, mutual shading of the crowns and shading of the background. The model has been validated for detecting oak trees infected by Phytophthora in $[12 \bullet \cdot]$ and olives trees infected by Xylella fastidiosa [3••]. Additionally, the DART RTM [57] has recently incorporated fluorescence emission in the radiative transfer of 3-D scenes. DART is able to simulate more complex 3-D scenes with different types of elements and distributions. Yet, models using a large set of input parameters could also increase the errors, so that further of this complex model validation over different types of ecosystems is still a delicate task.

\section{Energy Dissipated During Photosynthetic Downregulation}

A common way to quantify stress-related spectral changes is to use the photochemical reflectance index (PRI) calculated from the leaf spectral reflectance factor $R(\lambda)$, where $\lambda$ is the wavelength given in nanometers, as indicated in Eq. 3 :

$\mathrm{PRI}=\frac{R(531)-R(570)}{R(531)+R(570)}$

The two wavelengths are located on different sides of the green absorption minimum $(\lambda=550 \mathrm{~nm})$, where $\lambda=531 \mathrm{~nm}$ is the wavelength that is most affected by reversible changes [3.•] and $\lambda=570 \mathrm{~nm}$ is a reference wavelength where the typical absorption of other pigments of a green leaf is the same as at $531 \mathrm{~nm}$. The diurnal variation of the PRI is mainly driven by the mentioned changes in the xanthophyll cycle $[58,59]$ which are considered facultative changes in pigments. The PRI is also proportional to the chlorophyll and carotenoid ratio relative to the energy status and photosynthetic activities associated with changes in chlorophyll/carotenoid ratios throughout foliar development, ageing or stress [60]. In seasonal time scales (i.e. over weeks and months), the PRI variation thus combines changes in the xanthophyll cycle and changes in the pools of carotenoids and chlorophylls [60-62], which are considered constitutive changes in pigments. Recent studies have shown that these constitutive changes in pigment pool size have a dominant influence on the chlorophyll/carotenoid index (CCI, a modified PRI calculated using the chlorophyll absorption band as reference) over long periods $[63,64]$.

The tracking of LUE and photosynthetic performance via the PRI has been extensively explored over the last two decades. The PRI is a good predictor of photosynthetic efficiency and the connection between this index and dynamic photoprotection is well established at leaf level across species, functional types and nutrient treatments. The PRI accounted for about $60 \%$ of the variability of LUE at the leaf, canopy and ecosystem levels in unique exponential relationships for all the vegetation types studied $[65,66]$. It tracks the rapid physiological changes that are usually difficult to follow in evergreen species using indices of greenness and canopy structure, such as the normalized difference vegetation index (NDVI) [58, 59, 65-67]. Furthermore, the PRI is a good indicator of the photosynthetic apparatus across functional types and 
spatiotemporal scales $[65,68 \bullet \cdot]$ and has detected the reactivation of photosynthesis from winter stress in evergreen species $[63,64,69]$. The effects of seasonal drought on the photosynthetic apparatus have also been detected by satellite-based PRI [70, 71]. Maximum $\mathrm{CO}_{2}$ assimilation has been efficiently estimated by the PRI under severe drought conditions [72]. In addition, Rossini et al. [73] demonstrated that changes in the PRI were correlated with water stress in maize. Photosynthetic variability induced by heat and drought is simultaneously accompanied by complex physiological and biochemical processes that could, however, constrain the PRI-based estimation of the photosynthetic apparatus.

However, scaling of the PRI from leaf to canopy level requires considering numerous factors other than leaf biochemistry. While generally referred to as canopy structural effects, they also include the influence of measurement directionality, mixing of the spectra of the various canopy components and complex illumination conditions. This refers to effects caused by the shift from measuring a well-characterized, uniform target to working under natural illumination with a target composed of a large number of individual and directional scatterers. Indeed, multiple scattering in vegetation can be calculated using basic canopy structural information and the harmonic mean of leaf spectral reflectance at the two wavelengths used in the index. Unfortunately, the other factors are more difficult to quantify, may co-vary with changes in view or sun angle (e.g. visibility of soil background, a fraction of shaded leaves in sensor field of view and blue sky irradiance on the visible leaves) and are difficult to separate in empirical data.

To address this major research gap, various studies have proposed different methods for minimizing background and illumination effects on the PRI. An option is to use the illumination-corrected PRI (DeltaPRI) proposed by Takala and Mõttus [74] using the relationship between the PRI and the shadow fraction. According to this study, illuminationinduced effects are nearly half of the observed dynamic range of canopy PRI calculated using high spatial resolution airborne imaging spectroscopy data (less than 2-m resolution). Some authors have demonstrated the need to consider modified PRI formulations (such as the $\mathrm{PRI}_{512}$ index) that are less affected by structural components to detect vegetation stress in forest canopies [14]. Others have focused on improving the PRI to decrease the influence of these physiological and physical factors that hamper the detection of photosynthetic activity [68••]. The differential PRI is one of these corrections obtained by subtracting dark-state PRI from light-exposed PRI [75, 76], by subtracting predawn PRI from midday PRI [77], or by subtracting the actual PRI from the theoretical PRI calculated by RTM inversion techniques [78]. The DeltaPRI can eliminate the impacts of canopy structure and foliar pigments on PRI interpretations. In addition to dynamic photosynthetic downregulation, the PRI also reflects long-term photoprotective mechanisms apparent as changes in leaf pigment pools, which cannot be neglected since they affect the reference band at $570 \mathrm{~nm}$. To correct for this and detect photoprotection, the unstressed (i.e. predawn) PRI value needs to be subtracted from leaf measurements, which can be further elaborated to deconvolving daily and seasonal changes [79]. Unfortunately, this task requires multiple successful image acquisitions in a single day, which may not always be feasible. The consistency of the relationships between PRI, LUE and ecosystemic $\mathrm{CO}_{2}$ uptake [66] suggests a surprising degree of 'functional convergence' of biochemical, physiological and structural components that affect plant and carbon fluxes. As an alternative to the PRI, it has been proposed to integrate the whole spectral area affected by the downregulation (the 507-556-nm region) [80]. The xanthophyll cycle status can also be retrieved by inverting the recent modifications of the PROSPECT leaf optical model (PROSPECT-D [81] and Fluspect-CX [82]. These methods, which are computationally more complex, have shown promising results, but are nevertheless hindered by the canopy structural effects.

\section{Spectral Alterations Associated with Pigment Content Variation}

The main spectral regions sensitive to pigment absorption are located between 400 and $700 \mathrm{~nm}$ where the light spectrum useful for plant is largest $[18,83]$. This determines the absorption of natural light by vegetation. The red edge region has also been demonstrated to change with chlorophyll concentration and quick photosynthetic rate changes $[84,85]$. Hence, the main difficulty of remote pigment assessment is to disentangle the signals related to individual pigment and structural changes in plant canopies. Retrieval methods need to account for this overlap, especially when differentiating between chlorophyll and other pigment groups [86, 87].

Traditional remote sensing approaches to assess pigment concentration in heterogeneous forest areas have mainly focused on establishing empirical relationships between pigment concentration values measured in the field and vegetation index results of the combination of spectral bands. The use of vegetation indices is a popular choice to reduce unwanted structural, atmospheric and background effects at the canopy level $[59,88]$. The development of indices for quantifying pigment concentration is based on the known location of spectral features related to specific absorptions [89]. While these indices are based on the leaf spectral signal as a result of pigment concentration, their performance can decrease when applied to canopy image data where the mixed-pixel signal is affected by woody elements, canopy structure, crown architecture, the understory and soil background [90]. Croft et al. [88] reviewed the performance of indices used at both the leaf and canopy scales for both conifer and broadleaf species. 
Several studies have attempted to estimate pigment concentration through empirical approaches correlating broadband vegetation indices calculated from multispectral satellite imagery with field data [88]. Although these methods are appropriate for assessing large areas, the use of narrowband spectral information, typically provided by hyperspectral sensors, is suggested as the best procedure for pigment estimation where spectral responses are provided as narrow signal features [91]. Another limitation of traditional empirical methods based on vegetation indices is their poor performance in forest areas with high structural complexity. Croft et al. [88] demonstrated that the performance of broad and narrowband indices varies significantly for different forest structures. The effect of canopy structure and soil background on the performance of methods relying on vegetation indices has also been demonstrated through RTM $[92,93]$. To minimize the level of uncertainty in the predictions based on only a few spectral bands, methods using the full information acquired by hyperspectral systems in numerous continuous narrow bands have been developed [94]. They make it possible to conduct an extended analysis over multiple spectral regions and to quantify spectral peaks affected by both biochemistry and structure through continuum removal analysis and band depth normalizations [95-97].

Some statistical approaches that have been applied to hyperspectral imagery do not require previous knowledge of the location of spectral features. They range in complexity level from simple models such as linear discriminant analysis to complex machine learning techniques and neural networks. Although statistical models are very accurate locally, they can only be applied to the areas they were developed for and are not readily applicable to other sites and vegetation types [88, 98].

In search of more synoptic approaches, several authors have used RTM with various degrees of success. Model developments since the early 1990 s opened the possibility of integrating structural and biophysical data into the radiative transfer scheme, thereby providing the means to understand the effects of the different components on the overall reflectance signal. The development of leaf models, simulating the leaf spectral response as a function of its main structural components including chlorophyll content and later carotenoids, provided a tool to explore more universally applicable methods [99, 100]. Leaf spectrum simulations can be used as input in canopy models that consider the vegetation structure and background properties at different degrees of complexity [87]. Models can be either inverted to derive input values from image spectra [101] or used as a tool to develop robust algorithms based on vegetation indices. Although there is extensive literature documenting pigment absorption spectra and indices to use with leaf spectral data, methods developed at the leaf level are not ready to be used with canopy reflectance [6]. The effect of viewing and illumination geometry and the arrangement of the different elements on the ground and their spectral signal need to be considered [14, $92,93,102]$. Models simulate canopy reflectance with varying levels of detail. They range from 1-D models where the canopy layer is considered a continuous medium with a homogeneous composition to three-dimensional models that allow the representation of heterogenous discontinuous canopies with a very high level of detail [103]. The selection of the model to use is a compromise among the level of detail needed to properly describe the study area, input data availability and computational requirements needed to conduct the simulations or the model inversion. Homogeneous and continuous canopies composed of a single species can be assessed using 1-D models [93, 104, 105]. Discontinuous canopies and areas where specific vegetative components impart an important effect on overall reflectance (e.g. woody material) require accounting for the contribution of the canopy structure effects on radiative transfer schemes to obtain accurate assessments $[87,106,107]$.

\section{Conclusion, Gaps and Future Prospects}

\section{Data Acquisition and Quality}

There is consensus in the remote sensing community on the lack of availability of high spatial, spectral and temporal resolution VIS, NIR and TIR data [108•]. The highest spectral resolution in satellites with regular acquisition schedule is currently provided by MODIS while the highest spatial resolution is provided by Sentinel and the highest temporal range by Landsat. The spatial, spectral and temporal resolutions of satellite sensors constrain the reliability of monitoring plant biochemical variables such as pigment content or LAI at different spatial and temporal scales [109]. Several TIR sensors have been launched for Earth Observation (EO) purposes since the development of the first experimental HCMM TIR mission in the late 1970s. However, most of these sensors provide TIR data at low spectral and spatial resolutions. Applications of TIR data for studies on natural resources were boosted by the launch of Landsat-4 in the early 1980s, which included the first TIR sensor at a high spatial resolution. The launch of ASTER in December 1999 was a further step towards TIR applications because of its unique multispectral TIR characteristics (five TIR bands at high spatial resolution). The ECOsystem Spaceborne Thermal Radiometer Experiment on Space Station (ECOSTRESS) was recently mounted on the International Space Station (ISS) to monitor plant processes from space and is providing multispectral TIR imagery in five spectral bands at a spatial resolution below $100 \mathrm{~m}$ (ecostress.jpl.nasa.gov). Other future TIR missions such as Copernicus' Sentinel-8 or NASA's HyspIRI may also include multispectral capabilities at high spatial 
resolutions. In spite of these EO advances, significant gaps remain which clearly need addressing.

The aforementioned limitations of EO satellites for TIR applications requiring high spatial/spectral/temporal resolutions have typically been solved by using aerial remote sensing technologies. The procedure has been to use broadband, multispectral and hyperspectral TIR sensors mounted on planes under well-controlled conditions. This makes it possible to organize dedicated field campaigns for the acquisition of high-quality thermal imagery. Since the development of the thermal infrared multispectral scanner (TIMS) in the early 1980s [110], various airborne multi-/hyperspectral TIR sensors have operated in dedicated field campaigns. Some examples are the MODIS/ASTER (MASTER) simulator, the Spatially Enhanced Broadband Array Spectrograph System (SEBASS), the Airborne Hyperspectral Scanner (AHS), the Thermal Airborne Spectrographic Imager (TASI) and the Hyperspectral Thermal Emission Spectrometer (HyTES). SEBASS and HyTES have been used to identify plant species [28], AHS has been used to detect water stress in an olive orchard [111•] and MASTER has been used to assess LST variability and crop stress [112].

Given that dedicated field campaigns using high-quality airborne sensors incur high costs, proximal remote sensing using unmanned aerial vehicles (UAVs) has rapidly developed in recent years. However, due to their low load capacity, UAVs do not allow configurations using heavy instruments. In practice, small-sized and uncooled TIR cameras are currently used for thermal monitoring with UAVs. These uncooled microbolometer TIR cameras (FLIR Tau 2 or Thermoteknix MicroCAM 3) operate without an active temperature stabilization component, which can lead to LST retrievals whose precision is too low for some agricultural applications $[113,114]$. This problem may be partly solved by applying dedicated corrections to the data acquired with the uncooled TIR instrument [114]. However, the calibration of uncooled TIR cameras to absolute temperature measurement is a time-consuming and complex process [115].

The rapid development of new hyperspectral sensors to be carried onboard manned airborne and UAV platforms has given rise to the retrieval of high spatial resolution SIF at local scales, which is becoming a novel area of research $[12 \bullet \cdot, 54$, $114,115]$. Some of the in situ-based SIF measuring systems currently tested are FloX, JB Hyperspectral, PhotoSpec, Piccolo and HyScreen. Fluorescence data previously amassed from space were collected on missions not purposely designed for SIF but employing hyperspectral sensors such as OCO-2, GOME or TANSO/GOSAT [116]. However, it remains very challenging to cover the large areas required for forest monitoring analysis at a very high resolution. The measurement of SIF requires highly accurate radiance and retrieval methods reliant on instrument characterization and measurement setups and protocols. This has hitherto been the main limitation for studying the physiological condition of forest canopies in higher detail, as current available satellite sensors are limited by their spatial and spectral resolutions for SIF retrieval purposes.

To address the current gap in SIF collected at the global scale, the European Space Agency's Earth Explorer Mission of the 'Fluorescence Explorer' (FLEX) [117], the first mission designed to observe the photosynthetic activity of the vegetation layer on a global level, has recently been approved, with 2022 as the tentative launch date. For the first time, this mission will enable the assessment of the dynamics of photosynthesis in forest canopies through sun-induced fluorescence at 300-m spatial resolutions; in addition, it will be able to distinguish different fluorescence signals from PSI and PSII [118]. This offers a great advantage over current techniques used for photosynthesis monitoring based on green biomass estimations rather than on physiological processes acquired from conventional Earth-resource satellites. Detection of photosynthetic processes at the global level will change the scope of environmental and ecosystem management approaches and opens up a new line of research for ecological management and conservation. One of the major uncertainties to get there is understanding the relationship between SIF, PRI and LST towards estimating photosynthetic rates under different stress conditions. A recent experiment with passive proximal remote sensing at the leaf level demonstrates that it is feasible to estimate NPQ based on PRI and APAR, but under stress conditions, the relationship is strongly alternated [119]. The validation of these results at the canopy level will imply having into account the additional effect of other geometrical and structural components of the canopy and the background.

\section{From the Leaf to the Canopy: Upscaling Limitations}

Many constraints arise from the accurate scaling up and retrieval of PI from the leaf to the canopy. Such constraints are mainly related to the variations in plant functioning, canopy structure, atmosphere, pigments and soil background at different scales and have different impacts on the PI.

Atmospheric eddies induce variability in the thermal range that can limit the precision of LST retrievals [27, 120]. The contribution of pixels outside the field of view of the sensor (i.e. neighbour pixels) to the TIR radiance of the target pixel (i.e. adjacency effect) also induces uncertainty into the LST retrieval. Yet, the impacts of this effect on TIR measurements have yet to be adequately studied. Overall, precise characterization of surface emissivity is the limiting factor for accurate LST retrievals (emissivity uncertainties of $1 \%$ lead to LST uncertainties between 0.4 and $0.6 \mathrm{~K}$; Gomis-Cebolla et al. [121]). Fortunately, most of these impacts are somehow minimized over green vegetation because of its thermal homogeneity and high emissivity. However, emissivity characterization over dry (i.e. senescent) vegetation is more problematic, with a high 
impact on LST [122]. The scaling issue is still problematic in some applications because spectral features observed at the leaf level from in situ or laboratory measurements disappear at the metre scale when using airborne data [123].

The greatest challenges with the routine use of the PRI in vegetation health monitoring at the global scales lie in the difficulty of separating the long- and short-term dynamic components in the PRI and the difficulty in scaling up the index from canopy to leaf level. Solving these issues may require evaluating the full spectral information available in the region affected by the dynamic photoprotection processes (505$560 \mathrm{~nm}$ ) instead of focusing on a single index, or at the very least reformulating the PRI. We also need more research on scaling with a full description of leaf optics as well as comprehensive and temporally extensive calibrated leaf-level measurements to accompany remote spectral imagery. Further research is warranted to better understand the spectral response produced by the temporal and spatial dynamics of the photosynthetic activity so that it can be generalized to the ecosystemic and biospheric scales. In short, these problems are related to the structural differences of canopies, the varying 'background effects' (e.g. soil colour, moisture, shadows, the presence of other non-green landscape components), the effects of seasonality or the signals derived from variations in illumination and viewing angles.

One of the main challenges for scaling up chlorophyll fluorescence is the establishment of a relationship between leaf chlorophyll fluorescence and satellite-based measurements. In recent years, passive methods for remotely measuring chlorophyll fluorescence have been developed and applied. Fieldportable pulse amplitude modulated (PAM) devices have been widely applied to individual leaves. They provide an approach for bottom-up validation of steady-state fluorescence yield $\left(F_{\mathrm{s}}\right)$ for canopy photosynthesis models. Alternatively, $F_{\mathrm{s}}$ can also be measured with a FluorPen FP100 (Photon Systems Instruments, Brno, Czech Republic). Although measurements taken with both fluorescence instruments differ from airborne SIF retrievals, leaf data have been successfully used as a fieldlevel assessment in vegetation health analysis [12••, 121]. However, fluorescence is a low-intensity signal that overlaps with the much brighter red and near-infrared reflected radiation. These methods are designed to disentangle both signals, providing an indirect measure of fluorescence. Early on, it became clear that it was necessary to have a way of validating the retrievals or, at least, to have an estimate of the order of magnitude of the expected fluorescence signal. This need led to the design of a clip that allowed an attached leaf sample to be fully illuminated by natural sunlight, inducing photosynthesis; yet, at the same time it blocked the overlapping light fluorescence, providing a direct measurement of the emitted fluorescence from 650 to $850 \mathrm{~nm}$ and discriminating between the contribution of the red and far-red emission peaks. The FluoWat leaf clip was proposed by [124] and provided measurements of other leaf optical properties, such as reflectance, transmittance and, indirectly, absorbance and absorbed photosynthetically active radiation (APAR), as well as fluorescence yield. These parameters have made it possible to validate retrieval algorithms, helped to fine-tune leaf RTMs that include fluorescence emission and been used as a basis for upscaling from leaf to canopy. Similar challenges have been found for scaling up leaf pigment content to the canopy. Pigment leaf data has been successfully retrieved using destructive biochemical analysis or indirect measurements measured with a SPAD chlorophyll meter [125]. However, when scaling pigment content data from leaf to canopy level, the heterogeneity in pigment composition and canopy structure contribute to a higher variation of pigments in the canopy.

On balance, the uncertainty of scaling up PI from the leaf to the canopy requires special attention [126]. Special care needs to be applied to standardized retrieval methods for different leaf types (i.e. broad leaves and needles) and spatial sampling strategies that can be combined with airborne or satellite imagery. Other important challenges are related to assessments at the canopy scale and over larger areas using imagery. There is still a limited number of studies that have attempted to assess mixed forest areas with high species diversity with varying structural and composition properties. Previous studies have demonstrated that the main spectral differences found in mixed forests were the result of species composition and not pigment concentration [127]. This is especially relevant in high-production tropical forests considered to be the 'lungs of the Earth' and highly significant for carbon balance accounting at the global scale.

Future direction to solve these limitations is the improvement of RTM, incorporating new modules accounting for canopy structural effects and additional biochemical components of the leaf. At the canopy level, 3D models and data derived from active sensor imagery (e.g. LiDAR) may overcome some of the aforementioned limitations $[12 \bullet \bullet, 57]$. At the leaf level, recent improvements of PROSPECT, including anthocyanin content [81], and Fluspect, including xanthophyll content [82], may provide a better understanding of physiological processes and vegetation dynamics.

Nevertheless, RTM modelling approaches are powerful but remain computationally demanding for complex environments, so they are limited to smaller areas. One of the most recent solutions proposed to overcome this limitation is the combined use of RTM with a surrogate machine learning or emulator reducing the processing time while preserving accuracy [128].

It can therefore be concluded that remote sensing enables the assessment of physiological indicators to detect vegetation health over large areas. The close link between vegetation temperature, leaf optical properties linked to pigment absorption and chlorophyll fluorescence emission with plant functioning opens a wide range of applications and methods to 
monitor vegetation health remotely. Current and future research should address the main challenges, focusing on the improvement of data quality and successful upscaling to consider the main drivers of plant physiology.

Funding Information The authors received funding provided by the FluorFLIGHT (GGR801) Marie Curie Fellowship, the QUERCUSAT and ESPECTRAMED projects (Spanish Ministry of Economy and Competitiveness), the Academy of Finland (grants 266152, 317387) and the European Research Council Synergy grant ERC-2013-SyG610028 IMBALANCE-P.

\section{Compliance with Ethical Standards}

Conflict of Interest Rocio Hernandez-Clemente, Alberto Hornero, Matti Mottus, Josep Penuelas, Victoria González-Dugo, Juan Carlos Jiménez, Lola Suárez, Luis Alonso and Pablo J. Zarco-Tejada state that there are no conflicts of interests to declare.

Human and Animal Rights This article does not contain any studies with human or animal subjects performed by any of the authors.

Open Access This article is distributed under the terms of the Creative Commons Attribution 4.0 International License (http:// creativecommons.org/licenses/by/4.0/), which permits unrestricted use, distribution, and reproduction in any medium, provided you give appropriate credit to the original author(s) and the source, provide a link to the Creative Commons license, and indicate if changes were made.

\section{References}

Papers of particular interest, published recently, have been highlighted as:

- Of importance

•. Of major importance

1. Martinelli F, Scalenghe R, Davino S, Panno S, Scuderi G, Ruisi P, et al. Advanced methods of plant disease detection. A review. Agron Sustain Dev. 2015;35:1-25. https://doi.org/10.1007/s13593-0140246-1.

2. Steyn WJ, Wand SJE, Holcroft DM, Jacobs G. Anthocyanins in vegetative tissues: a proposed unified function in photoprotection. New Phytol. 2002;155:349-61. https://doi.org/10.1046/j.14698137.2002.00482.x.

3.• Zarco-Tejada PJ, Camino C, Beck PSA, Calderon R, Hornero A, Hernández-Clemente R, et al. Previsual symptoms of Xylella fastidiosa infection revealed in spectral plant-trait alterations. Nat Plants. 2018. https://doi.org/10.1038/s41477-018-0189-7 This study provides a practical framework for evaluating the effectiveness of detecting pre-visual symptoms of Xylella fastidiosa infection using high-resolution hyperspectral images, thermal data and radiative transfer modelling.

4. Calderón R, Navas-Cortés JA, Zarco-Tejada PJ. Early detection and quantification of Verticillium wilt in olive using hyperspectral and thermal imagery over large areas. Remote Sens. 2015;7:5584 610. https://doi.org/10.3390/rs70505584.

5. López-López M, Calderón R, González-Dugo V, Zarco-Tejada PJ, Fereres E. Early detection and quantification of almond red leaf blotch using high-resolution hyperspectral and thermal imagery. Remote Sens. 2016;8:276. https://doi.org/10.3390/rs8040276.

6. Hernández-Clemente R, Navarro-Cerrillo RM, Zarco-Tejada PJ. Carotenoid content estimation in a heterogeneous conifer forest using narrow-band indices and PROSPECT+DART simulations. Remote Sens Environ. 2012;127:298-315. https://doi.org/10. 1016/j.rse.2012.09.014.

7. Porcar-Castell A, Tyystjärvi E, Atherton J, van der Tol C, Flexas J, Pfündel EE, et al. Linking chlorophyll a fluorescence to photosynthesis for remote sensing applications: mechanisms and challenges. J Exp Bot. 2014;65:4065-95. https://doi.org/10.1093/jxb/ eru191.

8. Gates DM. Leaf temperature and transpiration 1. Agron J. 1964;56: 273-7. https://doi.org/10.2134/agronj 1964 . $00021962005600030007 \mathrm{x}$.

9. Möller M, Alchanatis V, Cohen Y, Meron M, Tsipris J, Naor A, et al. Use of thermal and visible imagery for estimating crop water status of irrigated grapevine. J Exp Bot. 2007;58:827-38. https:// doi.org/10.1093/jxb/erl115.

10. Reinert S, Bögelein R, Thomas FM. Use of thermal imaging to determine leaf conductance along a canopy gradient in European beech (Fagus sylvatica). Tree Physiol. 2012;32:294-302. https:// doi.org/10.1093/treephys/tps017.

11. Irmak S, Haman DZ, Bastug R. Determination of crop water stress index for irrigation timing and yield estimation of corn. Agron J. 2000;92:1221-7. https://doi.org/10.2134/agronj2000.9261221x.

12.• Hernández-Clemente R, North PRJ, Hornero A, Zarco-Tejada PJ. Assessing the effects of forest health on sun-induced chlorophyll fluorescence using the FluorFLIGHT 3-D radiative transfer model to account for forest structure. Remote Sens Environ. 2017;193: 165-79. https://doi.org/10.1016/j.rse.2017.02.012 Suggests a novel approach for assessing forest health using sun-induced chlorophyll fluorescence and 3-D radiative transfer modelling.

13. Smigaj M, Gaulton R, Suárez JC, Barr SL. Canopy temperature from an unmanned aerial vehicle as an indicator of tree stress associated with red band needle blight severity. For Ecol Manag. 2019;433:699-708. https://doi.org/10.1016/j.foreco.2018.11.032.

14. Hernández-Clemente R, Navarro-Cerrillo RM, Suárez L, Morales F, Zarco-Tejada PJ. Assessing structural effects on PRI for stress detection in conifer forests. Remote Sens Environ. 2011;115: 2360-75. https://doi.org/10.1016/j.rse.2011.04.036.

15. Lambers H, Chapin FS, Pons TL. Leaf energy budgets: effects of radiation and temperature. In: Lambers H, Chapin FS, Pons TL, editors. Plant physiological ecology. New York: Springer New York; 1998. p. 210-29.

16. Peñuelas J, Bartrons M, Llusia J, Filella I. Sensing the energetic status of plants and ecosystems. Trends Plant Sci. 2015;20:528 30. https://doi.org/10.1016/j.tplants.2015.07.002.

17. Tuominen J, Lipping T, Kuosmanen V, Haapanen R. Remote sensing of forest health. Geosci Remote Sens. 2009. https://doi.org/10. 5772/8283 This review summarizes forest health definitions and the use of vegetation indices extracted from remote sensing data.

18. Lichtenthaler HK. Vegetation stress: an introduction to the stress concept in plants. J Plant Physiol. 1996;148:4-14. https://doi.org/ 10.1016/S0176-1617(96)80287-2.

19. Lichtenthaler, H.K.: [34] Chlorophylls and carotenoids: pigments of photosynthetic biomembranes. In: Methods in enzymology. pp. 350-382. Academic Press (1987).

20. Demmig-Adams B, Gilmore AM, Adams WW. Carotenoids 3: in vivo function of carotenoids in higher plants. FASEB J Off Publ Fed Am Soc Exp Biol. 1996;10:403-12.

21. Chalker-Scott L. Environmental significance of anthocyanins in plant stress responses. Photochem Photobiol. 1999;70:1-9. https:// doi.org/10.1111/j.1751-1097.1999.tb01944.x. 
22. Barker DH, Seaton GGR, Robinson SA. Internal and external photoprotection in developing leaves of the CAM plant Cotyledon orbiculata. Plant Cell Environ. 1997;20:617-24. https://doi.org/10.1111/j.1365-3040.1997.00078.x.

23. Herold B, Truppel I, Zude M, Geyer M. Spectral measurements on 'Elstar' apples during fruit development on the tree. Biosyst Eng. 2005;2:173-82. https://doi.org/10.1016/j.biosystemseng.2005.03. 005 .

24. Robinson R. Formation of anthocyanins in plants. Nature. 1936;137:172-3. https://doi.org/10.1038/137172a0.

25. Schaberg PG, van den Berg AK, Murakami PF, Shane JB, Donnelly JR. Factors influencing red expression in autumn foliage of sugar maple trees. Tree Physiol. 2003;23:325-33. https://doi. org/10.1093/treephys/23.5.325.

26. Zarco-Tejada PJ, Miller JR, Mohammed GH, Noland TL. Chlorophyll fluorescence effects on vegetation apparent reflectance: I. Leaf-level measurements and model simulation. Remote Sens Environ. 2000;74:582-95. https://doi.org/10.1016/ S0034-4257(00)00148-6.

27. Sobrino JA, Frate FD, Drusch M, Jiménez-Muñoz JC, Manunta P, Regan A. Review of thermal infrared applications and requirements for future high-resolution sensors. IEEE Trans Geosci Remote Sens. 2016;54:2963-72. https://doi.org/10.1109/TGRS. 2015.2509179.

28. Ribeiro da Luz B, Crowley JK. Spectral reflectance and emissivity features of broad leaf plants: prospects for remote sensing in the thermal infrared (8.0-14.0 $\mu \mathrm{m})$. Remote Sens Environ. 2007;109: 393-405. https://doi.org/10.1016/j.rse.2007.01.008.

29. Li Z-L, Tang B-H, Wu H, Ren H, Yan G, Wan Z, et al. Satellitederived land surface temperature: current status and perspectives. Remote Sens Environ. 2013;131:14-37. https://doi.org/10.1016/j. rse.2012.12.008

30. Jimenez-Munoz JC, Cristobal J, Sobrino JA, Soria G, Ninyerola $\mathrm{M}$, Pons X, et al. Revision of the single-channel algorithm for land surface temperature retrieval from Landsat thermal-infrared data. IEEE Trans Geosci Remote Sens. 2009;47:339-49. https://doi. org/10.1109/TGRS.2008.2007125.

31. Sobrino JA, Jimenez-Munoz JC, Soria G, Romaguera M, Guanter $\mathrm{L}$, Moreno J, et al. Land surface emissivity retrieval from different VNIR and TIR sensors. IEEE Trans Geosci Remote Sens. 2008;46:316-27. https://doi.org/10.1109/TGRS.2007.904834.

32. Gillespie A, Rokugawa S, Matsunaga T, Cothern JS, Hook S, Kahle AB. A temperature and emissivity separation algorithm for advanced spaceborne thermal emission and reflection radiometer (ASTER) images. IEEE Trans Geosci Remote Sens. 1998;36: 1113-26. https://doi.org/10.1109/36.700995.

33. Jiménez-Muñoz JC, Sobrino JA, Mattar C, Hulley G, Göttsche F. Temperature and emissivity separation from MSG/SEVIRI data. IEEE Trans Geosci Remote Sens. 2014;52:5937-51. https://doi. org/10.1109/TGRS.2013.2293791.

34. Hulley GC, Hook SJ, Baldridge AM. Investigating the effects of soil moisture on thermal infrared land surface temperature and emissivity using satellite retrievals and laboratory measurements. Remote Sens Environ. 2010;114:1480-93. https://doi.org/10. 1016/j.rse.2010.02.002.

35. French AN, Inamdar A. Land cover characterization for hydrological modelling using thermal infrared emissivities. Int J Remote Sens. 2010;31:3867-83. https://doi.org/10.1080/01431161.2010. 483491

36. Borel C. Error analysis for a temperature and emissivity retrieval algorithm for hyperspectral imaging data. Int J Remote Sens. 2008;29:5029-45. https://doi.org/10.1080/01431160802036540.

37. Neinavaz E, Darvishzadeh R, Skidmore AK, Groen TA. Measuring the response of canopy emissivity spectra to leaf area index variation using thermal hyperspectral data. Int J Appl Earth
Obs Geoinf. 2016;53:40-7. https://doi.org/10.1016/j.jag.2016.08. 002.

38. Idso SB, Jackson RD, Pinter PJ, Reginato RJ, Hatfield JL. Normalizing the stress-degree-day parameter for environmental variability. Agric Meteorol. 1981;24:45-55. https://doi.org/10. 1016/0002-1571(81)90032-7.

39. Maes WH, Steppe K. Estimating evapotranspiration and drought stress with ground-based thermal remote sensing in agriculture: a review. J Exp Bot. 2012;63:4671-712. https://doi.org/10.1093/ jxb/ers 165 .

40. Bellvert J, Marsal J, Girona J, Zarco-Tejada PJ. Seasonal evolution of crop water stress index in grapevine varieties determined with high-resolution remote sensing thermal imagery. Irrig Sci. 2015;33:81-93. https://doi.org/10.1007/s00271-014-0456-y.

41. Gardner, B.R. (BP R., Nielsen, D.C., Shock, C.C.: Infrared thermometry and the crop water stress index. I. History, theory, and baselines. J Prod Agric USA (1992).

42. Jones PD, Briffa KR. Global surface air temperature variations during the twentieth century: part 1, spatial, temporal and seasonal details. The Holocene. 1992;2:165-79.

43. Alchanatis V, Cohen Y, Cohen S, Moller M, Sprinstin M, Meron $\mathrm{M}$, et al. Evaluation of different approaches for estimating and mapping crop water status in cotton with thermal imaging. Precis Agric. 2010;11:27-41. https://doi.org/10.1007/s11119009-9111-7.

44. Jackson RD, Idso SB, Reginato RJ, Pinter PJ. Canopy temperature as a crop water stress indicator. Water Resour Res. 1981;17:11338. https://doi.org/10.1029/WR017i004p01133.

45. Moran MS, Clarke TR, Inoue Y, Vidal A. Estimating crop water deficit using the relation between surface-air temperature and spectral vegetation index. Remote Sens Environ. 1994;49:24663. https://doi.org/10.1016/0034-4257(94)90020-5.

46. Plascyk JA. The MK II Fraunhofer line discriminator (FLD-II) for airborne and orbital remote sensing of solar-stimulated luminescence. Opt Eng. 1975;14:144339. https://doi.org/10.1117/12. 7971842.

47. Maier SW, Günther KP, Stellmes M. Sun-induced fluorescence: a new tool for precision farming. Digit Imaging Spectr Tech Appl Precis Agric Crop Physiol. asaspecialpubli. 2003:209-22. https:// doi.org/10.2134/asaspecpub66.c16.

48. Moya I, Daumard F, Moise N, Ounis A, Goulas Y. First airborne multiwavelength passive chlorophyll fluorescence measurements over La Mancha (Spain) fields. Second Recent Adv Quant Remote Sens. 2006:820-5.

49. Alonso L, Gomez-Chova L, Vila-Frances J, Amoros-Lopez J, Guanter L, Calpe J, et al. Improved Fraunhofer line discrimination method for vegetation fluorescence quantification. IEEE Geosci Remote Sens Lett. 2008;5:620-4. https://doi.org/10.1109/LGRS. 2008.2001180.

50. Meroni M, Rossini M, Guanter L, Alonso L, Rascher U, Colombo $\mathrm{R}$, et al. Remote sensing of solar-induced chlorophyll fluorescence: review of methods and applications. Remote Sens Environ. 2009;113:2037-51. https://doi.org/10.1016/j.rse.2009. 05.003 .

51. Guanter L, Rossini M, Colombo R, Meroni M, Frankenberg C, Lee J-E, et al. Using field spectroscopy to assess the potential of statistical approaches for the retrieval of sun-induced chlorophyll fluorescence from ground and space. Remote Sens Environ. 2013;133:52-61. https://doi.org/10.1016/j.rse.2013.01.017.

52. Miller, J.R., Berger, M., Alonso, L., Cerovic, Z., Goulas, Y., Jacquemoud, S., Louis, J., Mohammed, G., Moya, I., Pedros, R., Moreno, J.F., Verhoef, W., Zarco-Tejada, P.J.: Progress on the development of an integrated canopy fluorescence model. In: IGARSS 2003. 2003 IEEE International Geoscience and Remote Sensing Symposium. Proceedings (IEEE Cat. No.03CH37477). pp. 601-603 vol.1 (2003). 
53. Verhoef, W.: Extension of SAIL to model solar - induced canopy fluorescence spectra. Proc. 2nd Int. Workshop Remote Sens. Veg. Fluoresc. 17-19 Nov 2004 Montr. Can. Paris ESA 2004 ESA WPP 24218 P. (2004).

54. Vilfan N, van der Tol C, Muller O, Rascher U, Verhoef W. Fluspect-B: a model for leaf fluorescence, reflectance and transmittance spectra. Remote Sens Environ. 2016;186:596-615. https://doi.org/10.1016/j.rse.2016.09.017.

55. Zarco-Tejada PJ, Morales A, Testi L, Villalobos FJ. Spatiotemporal patterns of chlorophyll fluorescence and physiological and structural indices acquired from hyperspectral imagery as compared with carbon fluxes measured with eddy covariance. Remote Sens Environ. 2013;133:102-15. https://doi.org/10. 1016/j.rse.2013.02.003.

56. van der Tol C, Verhoef W, Timmermans J, Verhoef A, Su Z. An integrated model of soil-canopy spectral radiances, photosynthesis, fluorescence, temperature and energy balance. Biogeosciences. 2009;6:3109-29. https://doi.org/10.5194/bg-63109-2009.

57. Gastellu-Etchegorry J, Lauret N, Yin T, Landier L, Kallel A, Malenovský Z, et al. DART: recent advances in remote sensing data modeling with atmosphere, polarization, and chlorophyll fluorescence. IEEE J Sel Top Appl Earth Obs Remote Sens. 2017;10:2640-9. https://doi.org/10.1109/JSTARS.2017.2685528.

58. Gamon, J. A., Peñuelas, J., Field, C.B.: A narrow-waveband spectral index that tracks diurnal changes in photosynthetic efficiency, (1992).

59. Penuelas, J., Filella, I., Gamon, J.: Assessment of photosynthetic radiation use efficiency with spectral reflectance., (1995).

60. Filella I, Porcar-Castell A, Munné-Bosch S, Bäck J, Garbulsky MF, Peñuelas J. PRI assessment of long-term changes in carotenoids/chlorophyll ratio and short-term changes in deepoxidation state of the xanthophyll cycle. Int J Remote Sens. 2009;30:4443-55. https://doi.org/10.1080/01431160802575661.

61. Porcar-Castell A, Garcia-Plazaola JI, Nichol CJ, Kolari P, Olascoaga B, Kuusinen N, et al. Physiology of the seasonal relationship between the photochemical reflectance index and photosynthetic light use efficiency. Oecologia. 2012;170:313-23. https://doi.org/10.1007/s00442-012-2317-9.

62. Sims DA, Gamon JA. Relationships between leaf pigment content and spectral reflectance across a wide range of species, leaf structures and developmental stages. Remote Sens Environ. 2002;81: 337-54. https://doi.org/10.1016/S0034-4257(02)00010-X.

63. Gamon JA, Huemmrich KF, Wong CYS, Ensminger I, Garrity S, Hollinger DY, et al. A remotely sensed pigment index reveals photosynthetic phenology in evergreen conifers. Proc Natl Acad Sci. 2016;113:13087-92. https://doi.org/10.1073/pnas. 1606162113.

64. Wong CYS, Gamon JA. Three causes of variation in the photochemical reflectance index (PRI) in evergreen conifers. New Phytol. 2015;206:187-95. https://doi.org/10.1111/nph.13159.

65. Garbulsky MF, Peñuelas J, Gamon J, Inoue Y, Filella I. The photochemical reflectance index (PRI) and the remote sensing of leaf, canopy and ecosystem radiation use efficiencies. A review and meta-analysis. Remote Sens Environ. 2011;115:281-97. https:// doi.org/10.1016/j.rse.2010.08.023.

66. Penuelas J, Garbulsky MF, Filella I. Photochemical reflectance index (PRI) and remote sensing of plant $\mathrm{CO} 2$ uptake. New Phytol. 2011;191:596-9. https://doi.org/10.1111/j.1469-8137. 2011.03791.x.

67. Stylinski CD, Gamon JA, Oechel WC. Seasonal patterns of reflectance indices, carotenoid pigments and photosynthesis of evergreen chaparral species. Oecologia. 2002;131:366-74. https:// doi.org/10.1007/s00442-002-0905-9.

68.• Zhang C, Filella I, Garbulsky MF, Peñuelas J. Affecting factors and recent improvements of the photochemical reflectance index
(PRI) for remotely sensing foliar, canopy and ecosystemic radiation-use efficiencies. Remote Sens. 2016;8:677. https://doi. org/10.3390/rs8090677 A practical guide detecting the main factors affecting the relationship between the PRI and the terrestrial gross primary productivity.

69. Wong CYS, Gamon JA. The photochemical reflectance index provides an optical indicator of spring photosynthetic activation in evergreen conifers. New Phytol. 2015;206:196-208. https://doi. org/10.1111/nph.13251.

70. Goerner A, Reichstein M, Rambal S. Tracking seasonal drought effects on ecosystem light use efficiency with satellite-based PRI in a Mediterranean forest. Remote Sens Environ. 2009;113:110111. https://doi.org/10.1016/j.rse.2009.02.001.

71. Vicca S, Balzarolo M, Filella I, Granier A, Herbst M, Knohl A, et al. Remotely-sensed detection of effects of extreme droughts on gross primary production. Sci Rep. 2016;6:1-13. https://doi.org/ 10.1038/srep28269.

72. Ripullone F, Rivelli AR, Baraldi R, Guarini R, Guerrieri R, Magnani $\mathrm{F}$, et al. Effectiveness of the photochemical reflectance index to track photosynthetic activity over a range of forest tree species and plant water statuses. Funct Plant Biol. 2011;38:17786. https://doi.org/10.1071/FP10078.

73. Rossini M, Fava F, Cogliati S, Meroni M, Marchesi A, Panigada $\mathrm{C}$, et al. Assessing canopy PRI from airborne imagery to map water stress in maize. ISPRS J Photogramm Remote Sens. 2013;86:168-77. https://doi.org/10.1016/j.isprsjprs.2013.10.002.

74. Takala TLH, Mõttus M. Spatial variation of canopy PRI with shadow fraction caused by leaf-level irradiation conditions. Remote Sens Environ. 2016;182:99-112. https://doi.org/10. 1016/j.rse.2016.04.028.

75. Gamon JA, Berry JA. Facultative and constitutive pigment effects on the photochemical reflectance index (PRI) in sun and shade conifer needles. Isr J Plant Sci. 2012;60:85-95. https://doi.org/ 10.1560/ijps.60.1-2.85.

76. Gamon JA, Surfus JS. Assessing leaf pigment content and activity with a reflectometer. New Phytol. 1999;143:105-17. https://doi. org/10.1046/j.1469-8137.1999.00424.x.

77. Magney TS, Huggins DR, Eitel JUH, Vierling LA, Garrity SR. Response of high frequency photochemical reflectance index (PRI) measurements to environmental conditions in wheat. Remote Sens Environ. 2016.

78. Suárez L, Zarco-Tejada PJ, Berni JAJ, González-Dugo V, Fereres E. Modelling PRI for water stress detection using radiative transfer models. Remote Sens Environ. 2009;113:730-44. https://doi.org/ 10.1016/j.rse.2008.12.001.

79. Mõttus M, Aragão L, Bäck J, Hernández-Clemente R, Maeda EE, Markiet V, et al. Diurnal changes in leaf photochemical reflectance index in two evergreen forest canopies. IEEE J Sel Top Appl Earth Obs Remote Sens. 2019:1-8. https://doi.org/10.1109/JSTARS. 2019.2891789.

80. Kovac D, Navratil M, Malenovsky Z, Stroch M, Spunda V, Urban O. Reflectance continuum removal spectral index tracking the xanthophyll cycle photoprotective reactions in Norway spruce needles. Fac Sci Med Health - Pap Part A. 2012:987-98. https:// doi.org/10.1071/FP12107.

81. Feret J-B, Gitelson A, Noble SD, Jacquemoud S. PROSPECT-D: towards modeling leaf optical properties through a complete lifecycle. Remote Sens Environ. 2017;193:204-15. https://doi. org/10.1016/j.rse.2017.03.004.

82. Vilfan N, Van der Tol C, Yang P, Wyber R, Malenovský Z, Robinson SA, et al. Extending Fluspect to simulate xanthophyll driven leaf reflectance dynamics. Remote Sens Environ. 2018;211:345-56. https://doi.org/10.1016/j.rse.2018.04.012.

83. Gitelson AA, Merzlyak MN. Signature analysis of leaf reflectance spectra: algorithm development for remote sensing of chlorophyll. 
J Plant Physiol. 1996;148:494-500. https://doi.org/10.1016/ S0176-1617(96)80284-7.

84. Carter GA, Knapp AK. Leaf optical properties in higher plants: linking spectral characteristics to stress and chlorophyll concentration. Am J Bot. 2001;88:677-84.

85. Hernández-Clemente R, Kolari P, Porcar-Castell A, Korhonen L, Mõttus M. Tracking the seasonal dynamics of boreal forest photosynthesis using EO-1 Hyperion reflectance: sensitivity to structural and illumination effects. IEEE Trans Geosci Remote Sens. 2016;54:5105-16. https://doi.org/10.1109/TGRS.2016.2554466.

86. Gitelson AA, Yacobi YZ, Schalles JE, Rundquist DC, Han L, Stark R, et al. Remote estimation of phytoplankton density in productive waters. Arch HydrobioI Spec Issues Adv Limnol Limnol Lake Manag. 2000;55(2000):121-36.

87. Hernández-Clemente R, Navarro-Cerrillo RM, Ramírez FJR, Hornero A, Zarco-Tejada PJ. A novel methodology to estimate single-tree biophysical parameters from 3D digital imagery compared to aerial laser scanner data. Remote Sens. 2014;6:11627-48. https://doi.org/10.3390/rs61111627.

88. Croft H, Chen JM, Zhang Y. The applicability of empirical vegetation indices for determining leaf chlorophyll content over different leaf and canopy structures. Ecol Complex. 2014;17:119-30. https://doi.org/10.1016/j.ecocom.2013.11.005.

89. Blackburn GA. Wavelet decomposition of hyperspectral data: a novel approach to quantifying pigment concentrations in vegetation. Int J Remote Sens. 2007;28:2831-55. https://doi.org/10. 1080/01431160600928625.

90. Kuusk A. Monitoring of vegetation parameters on large areas by the inversion of a canopy reflectance model. Int J Remote Sens. 1998;19:2893-905. https://doi.org/10.1080/014311698214334.

91. Broge NH, Mortensen JV. Deriving green crop area index and canopy chlorophyll density of winter wheat from spectral reflectance data. Remote Sens Environ. 2002;81:45-57. https://doi.org/ 10.1016/S0034-4257(01)00332-7.

92. Barton CVM, North PRJ. Remote sensing of canopy light use efficiency using the photochemical reflectance index: model and sensitivity analysis. Remote Sens Environ. 2001;78:264-73. https://doi.org/10.1016/S0034-4257(01)00224-3.

93. Haboudane D, Miller JR, Tremblay N, Zarco-Tejada PJ, Dextraze L. Integrated narrow-band vegetation indices for prediction of crop chlorophyll content for application to precision agriculture. Remote Sens Environ. 2002;81:416-26. https://doi.org/10.1016/ S0034-4257(02)00018-4.

94. Kokaly RF, Clark RN. Spectroscopic determination of leaf biochemistry using band-depth analysis of absorption features and stepwise multiple linear regression. Remote Sens Environ. 1999;67:267-87. https://doi.org/10.1016/S00344257(98)00084-4.

95. Curran PJ, Dungan JL, Peterson DL. Estimating the foliar biochemical concentration of leaves with reflectance spectrometry: testing the Kokaly and Clark methodologies. Remote Sens Environ. 2001;76:349-59. https://doi.org/10.1016/S00344257(01)00182-1.

96. Malenovský Z, Homolová L, Zurita-Milla R, Lukeš P, Kaplan V, Hanuš J, et al. Retrieval of spruce leaf chlorophyll content from airborne image data using continuum removal and radiative transfer. Remote Sens Environ. 2013;131:85-102. https://doi.org/10. 1016/j.rse.2012.12.015.

97. Schlerf M, Atzberger C, Hill J, Buddenbaum H, Werner W, Schüler G. Retrieval of chlorophyll and nitrogen in Norway spruce (Picea abies L. Karst.) using imaging spectroscopy. Int J Appl Earth Obs Geoinf. 2010;12:17-26. https://doi.org/10.1016/j. jag.2009.08.006.

98. Zhang Y, Chen JM, Miller JR, Noland TL. Leaf chlorophyll content retrieval from airborne hyperspectral remote sensing imagery.
Remote Sens Environ. 2008;112:3234-47. https://doi.org/10. 1016/j.rse.2008.04.005.

99. Jacquemoud S, Baret F. PROSPECT: a model of leaf optical properties spectra. Remote Sens Environ. 1990;34:75-91. https://doi. org/10.1016/0034-4257(90)90100-Z.

100. Hernandez-Clemente R, Navarro-Cerrillo RM, Zarco-Tejada PJ. Deriving predictive relationships of carotenoid content at the canopy level in a conifer forest using hyperspectral imagery and model simulation. IEEE Trans Geosci Remote Sens. 2014;52:520617. https://doi.org/10.1109/TGRS.2013.2287304.

101. Sampson PH, Zarco-Tejada PJ, Mohammed GH, Miller JR, Noland TL. Hyperspectral remote sensing of forest condition: estimating chlorophyll content in tolerant hardwoods. For Sci. 2003;49:381-91. https://doi.org/10.1093/forestscience/49.3.381.

102. Suárez L, Zarco-Tejada PJ, Sepulcre-Cantó G, Pérez-Priego O, Miller JR, Jiménez-Muñoz JC, et al. Assessing canopy PRI for water stress detection with diurnal airborne imagery. Remote Sens Environ. 2008;112:560-75. https://doi.org/10.1016/j.rse.2007.05.009.

103. Widlowski J-L, Pinty B, Lopatka M, Atzberger C, Buzica D, Chelle M, et al. The fourth radiation transfer model intercomparison (RAMI-IV): proficiency testing of canopy reflectance models with ISO-13528. J Geophys Res-Atmos. 2013;118:6869-90. https://doi.org/10.1002/jgrd.50497.

104. Zarco-Tejada PJ, Miller JR, Harron J, Hu B, Noland TL, Goel N, et al. Needle chlorophyll content estimation through model inversion using hyperspectral data from boreal conifer forest canopies. Remote Sens Environ. 2004;89:189-99. https://doi.org/10.1016/j. rse.2002.06.002.

105. Zarco-Tejada PJ, Miller JR, Mohammed GH, Noland TL, Sampson PH. Estimation of chlorophyll fluorescence under natural illumination from hyperspectral data. Int J Appl Earth Obs Geoinf. 2001;3:321-7. https://doi.org/10.1016/S0303-2434(01) 85039-X.

106. Demarez V, Gastellu-Etchegorry JP. A modeling approach for studying forest chlorophyll content. Remote Sens Environ. 2000;71:22638. https://doi.org/10.1016/S0034-4257(99)00089-9.

107. Yáñez-Rausell L, Malenovský Z, Rautiainen M, Clevers JGPW, Lukeš $\mathrm{P}$, Hanuš J, et al. Estimation of spruce needle-leaf chlorophyll content based on DART and PARAS canopy reflectance models. IEEE J Sel Top Appl Earth Obs Remote Sens. 2015;8: 1534 44. https://doi.org/10.1109/JSTARS.2015.2400418.

108. Sobrino JA, Frate FD, Drusch M, Jiménez-Muñoz JC, Manunta P, Regan A. Review of thermal infrared applications and requirements for future high-resolution sensors. IEEE Trans Geosci Remote Sens. 2016). doi:https://doi.org/10.1109/TGRS.2015. 2509179;54:2963-72 This review neatly summarizes the applicability of thermal infrared data for different applications, including vegetation condition.

109. Navarro-Cerrillo RM, Trujillo J, Sanchez de la Orden M, Hernández-Clemente R. Hyperspectral and multispectral satellite sensors for mapping chlorophyll content in a Mediterranean Pinus sylvestris L. plantation. Int J Appl Earth Obs Geoinf. 2014;26:8896. https://doi.org/10.1016/j.jag.2013.06.001.

110. Kahle, A.B.: The new airborne thermal infrared multispectral scanner (TIMS). Presented at the 1983 International Geoscience and Remote Sensing Symposium, August 31-September 2, 1983 January 1 (1983).

111. Sepulcre-Cantó G, Zarco-Tejada PJ, Jiménez-Muñoz JC, Sobrino JA, de Miguel E, Villalobos FJ. Detection of water stress in an olive orchard with thermal remote sensing imagery. Agric For Meteorol. 2006;136:31-44. https://doi.org/10.1016/j.agrformet. 2006.01.008 This study provides a practical example of how thermal data can be used to monitor water stress in plants.

112. Shivers SW, Roberts DA, McFadden JP. Using paired thermal and hyperspectral aerial imagery to quantify land surface temperature variability and assess crop stress within California orchards. 
Remote Sens Environ. 2019;222:215-31. https://doi.org/10.1016/ j.rse.2018.12.030.

113. Kusnierek K, Korsaeth A. Challenges in using an analog uncooled microbolometer thermal camera to measure crop temperature. Int J Agric Biol Eng. 2014;7:60-74. https://doi.org/10.25165/ijabe. v7i4.1041.

114. Ribeiro-Gomes K, Hernández-López D, Ortega JF, Ballesteros R, Poblete T, Moreno MA. Uncooled thermal camera calibration and optimization of the photogrammetry process for UAV applications in agriculture. Sensors. 2017;17:2173. https://doi.org/10.3390/ s17102173.

115. Budzier H, Gerlach G. Calibration of uncooled thermal infrared cameras. J Sens Sens Syst. 2015;4:187-97. https://doi.org/10. 5194/jsss-4-187-2015.

116. Guanter L, Frankenberg C, Dudhia A, Lewis PE, Gómez-Dans J, Kuze A, et al. Retrieval and global assessment of terrestrial chlorophyll fluorescence from GOSAT space measurements. Remote Sens Environ. 2012;121:236-51. https://doi.org/10.1016/j.rse.2012.02.006.

117. Kraft, S., Bello, U.D., Bouvet, M., Drusch, M., Moreno, J.: FLEX: ESA's Earth Explorer 8 candidate mission. In: 2012 IEEE International Geoscience and Remote Sensing Symposium. pp. 7125-7128 (2012).

118. Rossini M, Panigada C, Cilia C, Meroni M, Busetto L, Cogliati S, et al. Discriminating irrigated and rainfed maize with diurnal fluorescence and canopy temperature airborne maps. ISPRS Int J GeoInf. 2015;4:626-46. https://doi.org/10.3390/ijgi4020626.

119. Alonso L, Wittenberghe SV, Amorós-López J, Vila-Francés J, Gómez-Chova L, Moreno JF. Diurnal cycle relationships between passive fluorescence, PRI and NPQ of vegetation in a controlled stress experiment. Remote Sens. 2017;9:770. https://doi.org/10. 3390/rs9080770.

120. Balick, L.K., Jeffery, C.A., Henderson, B.G.: Turbulence-induced spatial variation of surface temperature in high-resolution thermal IR satellite imagery. In: Remote sensing for agriculture, ecosystems, and hydrology IV. pp. 221-231. International Society for Optics and Photonics (2003).

121. Gomis-Cebolla, J., Jiménez-Muñoz, J.C., Sobrino, J.A.: Extreme thermal episodes analyzed with MODIS products during the boreal winter (2000-2016). Rev Teledetec 0, 19-30 (2016). doi: https://doi.org/10.4995/raet.2016.5709.
122. Olioso A, Soria G, Sobrino J, Duchemin B. Evidence of low land surface thermal infrared emissivity in the presence of dry vegetation. IEEE Geosci Remote Sens Lett. 2007;4:112-6. https://doi. org/10.1109/LGRS.2006.885857.

123. Meerdink SK, Roberts DA, King JY, Roth KL, Dennison PE, Amaral $\mathrm{CH}$, et al. Linking seasonal foliar traits to VSWIR-TIR spectroscopy across California ecosystems. Remote Sens Environ. 2016;186:322-38. https://doi.org/10.1016/j.rse.2016.08.003.

124. Alonso, L., Gomez-Chova, L., Vila-Frances, J., Amoros-Lopez, J., Guanter, L., Calpe, J., Moreno, J.: Sensitivity analysis of the Fraunhofer line discrimination method for the measurement of chlorophyll fluorescence using a field spectroradiometer. In: 2007 IEEE International Geoscience and Remote Sensing Symposium. pp. 3756-3759 (2007).

125. Zarco-Tejada PJ, González-Dugo V, Williams LE, Suárez L, Berni JAJ, Goldhamer D, et al. A PRI-based water stress index combining structural and chlorophyll effects: assessment using diurnal narrow-band airborne imagery and the CWSI thermal index. Remote Sens Environ. 2013;138:38-50. https://doi.org/10.1016/ j.rse.2013.07.024.

126. Woodgate W, Jones SD, Suarez L, Hill MJ, Armston JD, Wilkes P, et al. Understanding the variability in ground-based methods for retrieving canopy openness, gap fraction, and leaf area index in diverse forest systems. Agric For Meteorol. 2015;205:83-95. https://doi.org/10.1016/j.agrformet.2015.02.012.

127. Asner GP, Martin RE, Ford AJ, Metcalfe DJ, Liddell MJ. Leaf chemical and spectral diversity in Australian tropical forests. Ecol Appl. 2009;19:236-53. https://doi.org/10.1890/08-0023.1.

128. Verrelst J, Rivera Caicedo JP, Muñoz-Marí J, Camps-Valls G, Moreno J. SCOPE-based emulators for fast generation of synthetic canopy reflectance and sun-induced fluorescence spectra. Remote Sens. 2017;9:927. https://doi.org/10.3390/rs9090927.

Publisher's Note Springer Nature remains neutral with regard to jurisdictional claims in published maps and institutional affiliations. 